\title{
Life History Variables of Wild Troops of Formosan Macaques (Macaca cyclopis) in Kenting, Taiwan
}

\author{
HAI-YIN WU and YAO-SUNG LIN
} National Taiwan University

\begin{abstract}
A study on population dynamics of wild Formosan macaques (Macaca cyclopis) in Kenting, southern Taiwan, was conducted from March 1985 to August 1990. At first, only one monkey troop was studied. It fissioned in 1987 and both of the daughter troops have been observed since then. Total number of animals increased from 10 to 29 over the years, but the sizes of individual troops have never been more than 20 . Seasonality in breeding has been detected: copulations were concentrated in the period from November to January and $75 \%$ of all the 28 births occurred between April and June. Time of birth by parous females without offspring from the preceding year was earlier than that of lactating females. Young females gave their first births at 4 or 5 years of age. Total birth rate over the study period was 0.8 infant per female per year. Hunting was the main cause of death while natural mortality rate was low for the animals. There was only one adult male in each troop for most of the time. Troop males in the two daughter troops have been replaced two or three times in the three years by some solitary males that moved around in the area. The reproductive parameters of Formosan macaques in Kenting were found to be more similar to that of rhesus monkeys than to Japanese macaques. And a case of higher reproductive success in a high-ranking matriline was reported.
\end{abstract}

Key Words: Formosan macaque; Macaca cyclopis; Life history variables.

\section{INTRODUCTION}

The Formosan macaque (Macaca cyclopis), the largest endemic mammal species in Taiwan, is widely distributed in the mountainous area of the island. In the past few decades, due to lack of interests by native researchers in the study of wild macaques, only limited information on this species was known to the scientific community. In addition, the rough topography of its habitat, intensive hunting and human disturbance on the Formosan macaque also made this animal inaccessible. In recent years, some studies on the distribution and status of this species (LeE \& LiN, 1991; MASUI et al., 1986; POIRIER \& DAVIDSON, 1979; TANAKA, 1986) as well as surveys on the monkey populations in several protected areas (LIN \& LU, 1989, 1990; LU et al., 1991) were conducted. According to these reports, the population of Formosan macaques, although not as endangered as some other large mammals on the island, is threatened by habitat loss and illegal hunting especially outside the protected areas such as national parks and nature preserves.

Up to now, observations of the monkeys in Taipingshan area (eastern Taiwan) by several Japanese primatologists (KAWAMURA et al., 1988) and our study of the monkey troops in Kenting were the only two long-term field studies of the species. Our study was conducted in a nature preserve where hunting was prohibited since 1984. It provides us an opportunity to follow the population dynamics of small monkey troops after hunting pressure was lessened. General descriptions on behavior of the macaques and one case of fission in our study troop have been reported elsewhere (WU, 1986; WU et al., 1991). In this paper, we 
describe the results on the population dynamics of the study troops and discuss the relationship between some environmental and social factors and the observed patterns.

\section{STUDY AREA AND METHODS}

This study was conducted in the Hengchun Nature Preserve $\left(120^{\circ} 49^{\prime} \mathrm{E}, 21^{\circ} 58^{\prime} \mathrm{N}\right)$ within Kenting National Park on the southern tip of Taiwan. This preserve is measured 150 to $320 \mathrm{~m}$ in elevation and 150 ha in area. Many ridges and isolated blocks of uplifted coral reefs are scattered in this area which, incidentally, is the only natural scenery of uplifted coral reefs are scattered in this area which, incidentally, is the only natural scenery of uplifted coral reefs that remain intact in Taiwan. Subtropical monsoon forest covering the preserve and its surrounding area is also among a few lowland natural forests of Taiwan which are protected against human disturbance. Dominant species of the vegetation on top of the reefs are Aglaia formosana, Dryetes littoralis, Planchonella obovata, and Ficus benjamina, whereas those of that dominating forest patches between blocks of reefs are Diosyros maritima, $D$. philippinensis, Bischofia javanica, and $F$. benjamina. Fruits of these dominant species, figs, and new sprouts of several Ficus species which are also abundant in this area (such as F. irisana, $F$. benjamina, and $F$. wighiana), and leaves of Pueraria montana constitute the main food items for the macaques. Insects such as cicadas and caterpillars, when available, are also included in the diet.

According to the records of the Central Weather Bureau, annual precipitation in Hengchun area was about $2,200 \mathrm{~mm}$ and most rainfalls were concentrated during the rainy season from May to September. The magnitude and the months of peak precipitations of a given year were determined by frequency and time of typhoons in that year. Dry season lasted from October till the following April and the monthly rainfall in the dry season seldom exceeded $100 \mathrm{~mm}$. This period was also the time of strong seasonal wind and the wind speed may reach 10 to $17 \mathrm{~m} / \mathrm{sec}$. Mean annual temperature was $23^{\circ} \mathrm{C}$. In general, the climate at the study site is hot and rainy in summer, and cool and windy in winter (Fig. 1).
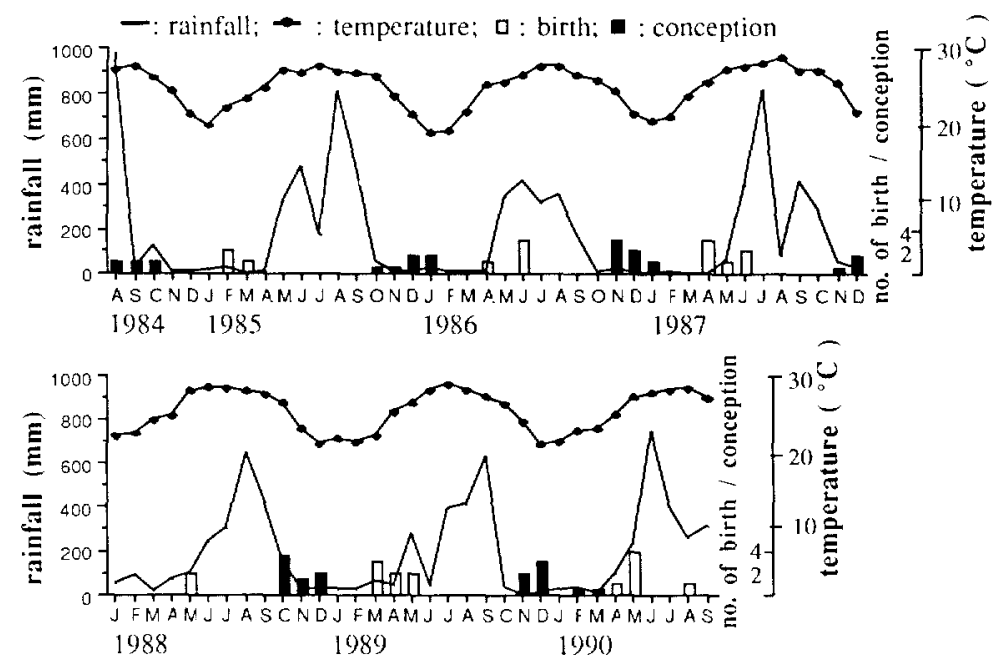

Fig. 1. Monthly distribution of births and conceptions in the study troops, and of rainfall and temperature of Hengchun (about $15 \mathrm{~km}$ north to the study area). 
The study site was part of the natural forest maintained by the Hengchun Branch of Taiwan Foresty Research Institute. Before 1984, the macaque population in the area was low because there was no control on illegal hunting. The establishment of the Kenting National Park in 1984 and the declaration of the Hengchun Nature Preserve not only protect the area against habitat destruction, but also reduce the hunting pressure.

The study period extends from March 1985 to August 1990. The macaque troops were censused and observed on a monthly basis with a total of 276 days $(2,579 \mathrm{hr})$ of field work. Binoculars (Leitz Trinovid 10 $\times 40$ ) and telescope (Bausch \& Lomb zoom $60 \mathrm{~mm}$ ) were used in field observations. All the animals in the study troops and solitary males were identified and given codes. Time and the participants of all sexual and social behaviors were recorded in detail.

One monkey troop ( $\mathrm{S}$ troop) was observed at the beginning of the study. Ten individuals (one adult male, three adult females each with a newborn offspring, and three subadult females estimated to be 3 years old) constituted the S troop. It split into two troops (S1 \& $\mathrm{S} 2$ troops) in mid-1987 and two adult macaques (male " ${ }^{\prime} O$ '" \& female " $U$," being released into this area by local people in 1986) joined S2 troop after the fission. After the fission, S1 troop remained the main focus of the study but observations on S2 troop were also made whenever possible. Outside the home ranges of the study troops, at least three macaque troops existed in nearby area, but no intertroop encounter was witnessed.

Demographic events occurring in the study troops were monitored. Newborns were sexed and their birthdates were estimated with an accuracy of no more than half-month's discrepancy. Conception time for each birth was estimated by substracting the average length of gestation (=5.5 months; PENG et al., 1973) from the time of birth. Interactions between solitary males and members of the study troops were noted. The dense canopy, rough terrain, and shyness of the animals made it difficult for a single observer to follow and observe the macaques within close distance. Therefore, most of the field records were obtained at specific spots where the macaques visited frequently, or when the observer was on top of some elevated reefs with good view of the area but at some distance away from the monkeys.

"Birth rate" was defined as the average number of infants born to a female per year. Total birth rate was defined as the ratio of total number of infants born in the six birth seasons to the sum of the numbers of fertile females during the same period. A female is included in the calculation of birth rate from the year of its first childbirth. The calculated birth rate may be overestimated since the reproductive potential of nulliparous but sexually mature females may be overlooked.

Copulation rate (total number of observed copulations divided by the total observation hours in each month) is used to indicate the intensity of mating activity of the macaques in each month. Only the copulation records of S1 troop between October 1987 and April 1990 were used because data on the sexual behavior of S and S2 troops were too scanty for analysis.

\section{RESULTS}

\section{Troop Size and Structure}

Total number of monkeys in the study troops increased from 10 to 29 over the 5.5 years. Annual growth rate of the local population varied from $-5 \%$ to $50 \%$ with an average of $25.2 \%$ (Table 1). 
Table 1. Age and sex compositions of the study troops.

\begin{tabular}{|c|c|c|c|c|c|c|c|c|c|c|c|c|c|c|}
\hline \multirow[b]{2}{*}{ Period } & \multicolumn{3}{|c|}{ Age: $0-1$ yr. } & \multicolumn{2}{|c|}{$1-2$ yr. } & \multicolumn{2}{|c|}{$2-3 \mathrm{yr}$} & \multicolumn{2}{|c|}{ Subadult $^{1)}$} & \multicolumn{2}{|c|}{ Adult } & \multirow[b]{2}{*}{ Troop size } & \multirow[b]{2}{*}{ Total } & \multirow[b]{2}{*}{ Annual change $(\%)$} \\
\hline & Sex: & or & 甲 & $\sigma$ & $q$ & $\overline{O^{\prime}}$ & & $\sigma$ & 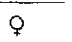 & 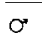 & $\bar{q}$ & & & \\
\hline Dec. 1985 & $\mathrm{~S}$ & 2 & 1 & & & & & & 3 & 1 & 3 & 10 & 10 & \\
\hline Dec. 1986 & S & 2 & 2 & 2 & 1 & & & & 2 & 1 & 4 & 14 & 14 & 40 \\
\hline \multirow[t]{2}{*}{ Dec. 1987} & S1 & 1 & 2 & 1 & 1 & 1 & 1 & & & 1 & 4 & 12 & & \\
\hline & $\mathrm{S} 2$ & 1 & 2 & & 1 & 1 & & & & 1 & 3 & 9 & 21 & 50 \\
\hline \multirow[t]{2}{*}{ Dec. 1988} & $\mathrm{S1}$ & & 2 & 1 & & 1 & 1 & & 1 & 2 & 3 & 11 & & \\
\hline & $\mathrm{S} 2$ & & & 1 & 2 & & 1 & 1 & & 1 & 3 & 9 & 20 & -5 \\
\hline \multirow[t]{2}{*}{ Dec. 1989} & S1 & 2 & 2 & & 2 & 1 & & 1 & 1 & 1 & 4 & 14 & & \\
\hline & $\mathrm{S} 2$ & 2 & 1 & & & 1 & 2 & 1 & $i$ & 1 & 3 & 12 & 26 & 30 \\
\hline \multirow[t]{2}{*}{ Aug. 1990} & $\mathrm{~S} 1$ & 2 & 2 & 1 & 2 & & 2 & 2 & & 1 & 4 & 16 & & \\
\hline & S2 & $1^{*}$ & & 2 & 1 & & & 2 & 3 & 1 & 3 & 13 & 29 & 11 \\
\hline
\end{tabular}

1) Males smaller than adults and nulliparous females are classified as subadults. ${ }^{*}$ Sex unknown.

Table 2. Troop males and their tenures of the troops.

\begin{tabular}{lllr}
\hline Troop & Animal code & Period as troop male & Tenure (months) \\
\hline S & $\circ \mathrm{M}^{1)}$ & Mar. 1985-Jun. 1987 & $>28$ \\
$\mathrm{~S} 1$ & $\circ \mathrm{M}$ & Jul. 1987- Nov. 1987 & 5 \\
& $\circ 2$ & Dec. 1987-Jun. 1989 & 19 \\
& $\circ 1^{2)}$ & Dec. 1988-Aug. 1990 & $>21$ \\
S2 & $\circ \mathrm{O}$ & Jul. 1987-Sept. 1988 & 15 \\
& $? ?^{3)}$ & Oct. 1988- Mar. 1989 & $?$ \\
& ơ $\mathrm{Y}$ & Apr. 1989-Aug. 1990 & $>17$ \\
\hline
\end{tabular}

1) $\propto \mathrm{M}$ was the original troop male in $\mathrm{S}$ troop; 2) o $1 \& \sigma^{\prime} 2$ coexisted as troop males in Sl troop between Dec. 1988 \& Jun. 1989; 3) troop male in S2 troop seemed to have changed three times before the takeover by $\sigma^{\circ}$.

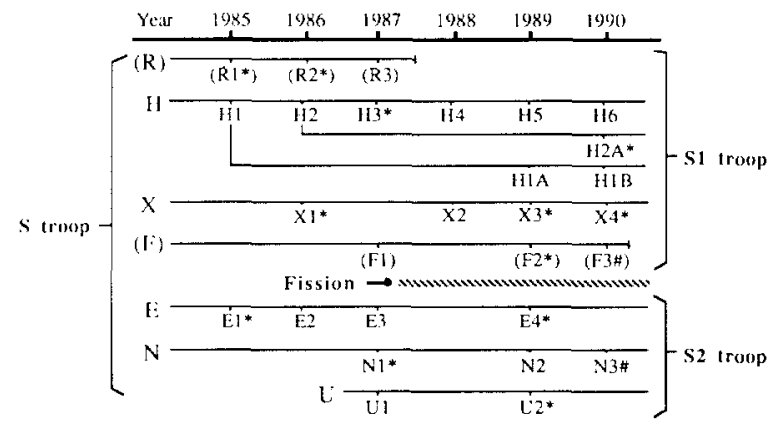

Fig. 2. Matrilineal kinships among members of the study troops $(*$ : male; \#: sex unknown; individuals in parentheses denote members who died or disappeared sometime during the study).

The sizes of the original study troop ( $\mathrm{S}$ troop) and of the two troops formed after the fission (S1 \& S2 troops) ranged from 10 to 16 (Table 1). The number of individuals in S troop increased from ten in 1985 to 19 before the fission in mid-1987. After the fission, sizes of the two daughter troops increased from 12 to 16 in S1 troop, and from 9 to 13 in S2 troop in three years. The matriarches of $S$ troop, their descendants, and the way of redistribution into two daughter troops after the fission are shown in Figure 2.

Each troop contained only one adult male most of the time, except during the period between December 1988 and June 1989 when two adult males coexisted in S1 troop. Adult males that have ever joined the study troops and their tenure of the troops are summarized in Table 2. Adult male to female sex ratio in each troop ranged from $2: 3$ to $1: 4$, or from $2: 4$ to $1: 6$ if nulliparous females older than 3 years were included as potential mates for males. The proportion of juveniles (less than 3 years old) in S troop was only 0.3 in 1985 
because there were only three babies of that year but no 1 - to 3 -year-old juveniles. The ratio increased to 0.5 in 1986. Similar ratio, which ranged from 0.44 to 0.58 , was observed in the two daughter troops from 1987 to 1989 . In 1990, however, the proportion in S1 troop became higher than that of the $S 2$ troop (0.56 vs. 0.30$)$.

\section{Sexual Maturation of Females}

Young female Formosan macaque gives birth for the first time at the age of 4 or 5 years. We followed the development of three females $(H 1, H 2, \& E 2)$ from birth to maturity. $H 1$, born in February 1985, underwent changes in sexual skin for the first time at 33 months of age. It had pronounced anogenital swelling in the mating season of 1988, and had consorted and mated with adult males. In May 1989, $H I$ gave birth to its first offspring at the age of 51.5 months. $H 2$, born in June 1986, underwent first sign of sexual swelling when it was 30 months old. It had exhibited extensive swelling and copulated with adult males at the age of 42 months, and gave birth to its first child when it was 50.5 months old. E2 went through those maturation events at about the same age as $\mathrm{H2}$, but was still nulliparous until the end of our study. Three other females, $X, N$, and $F$, also reached maturity and gave birth during the study. Although their actual ages were not known, it was estimated that they gave birth at the ages of 4 (for $X$ ) and 5 (for $F$ and $N$ ) years, respectively.

\section{BREEding SEASONALITY AND BiRTH}

Formosan macaques are seasonal breeders. A total of 304 copulations in S1 troop were observed between October 1987 and April 1990, and the copulation rate in each month ranged from 0 to 3.11 per observation hour (Fig. 3). Although copulations were observed in all the months except in February, June, and September, $90 \%$ of the mating activities were concentrated in the period between November and January.

Births in the study troops occurred from February to August, $75 \%$ took place between April and June. The estimated conception time took place between August and March, with the peak frequency occurring in November and December (Table 3). The pattern was consistent with the distribution of copulations. Between March 1985 and August 1990, 26 infants were born into the study troops. When we began our study on S troop in 1985, there were already two infants of about 1 month old. These two were also included in the birth record. Among the 28 births, 12 occurred in S troop, 11 in S1 troop, and 4 in S2 troop. Although sex ratio at birth varied with years, sex ratio of all the births of known sex over the 5 years $\left(12 \sigma^{\circ}\right.$ vs. $\left.14 q\right)$ was not significantly different from the $1: 1$ ratio $\left(\chi^{2}=0.154\right.$, $p>0.1$.

Total birth rate over the six birth seasons was 0.8 infant per female per year. Annual birth rates of S and S1 troops were higher than that of S2 troop (Table 4). The mean birth rate of $S$ troop over the period of three years $(1985-1987)$ was 0.95 . After the fission, the figure of S1 troop was significantly higher than that of S2 troop (0.89 vs. 0.44$)$.

Climatic conditions such as day length, temperature, and rainfall may affect the timing of reproduction of the macaques. Our data revealed that the distribution of conceptions was negatively correlated with day length $\left(r_{s}=-0.832, p<0.01\right)$. The climatic conditions preceding the months of peak conceptions are decreasing day length, decreasing temperature, and high level of rainfall (Fig. 1). Since rainfall may influence food abundance, and the fluctuations of monthly rainfall are greater than the gradual changes of monthly mean temperature and day length, a series of Spearman's rank correlation coefficients between 


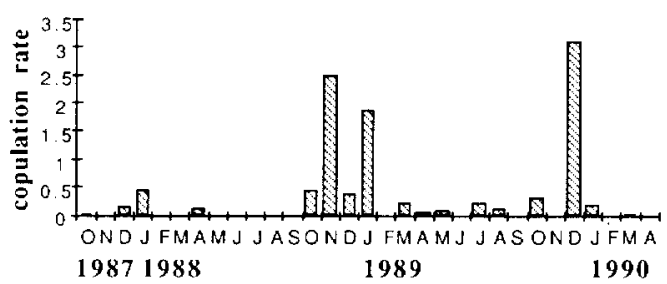

Fig. 3. Distribution of monthly copulation rate (No. of copulations/observation hour) in S1 troop in the period from October 1987 to April 1990.

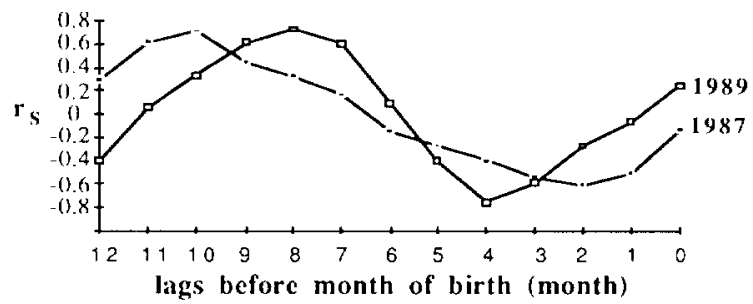

Fig. 4. Spearman's rank correlation coefficients between monthly distribution of births and monthly rainfall in 1987 and 1989 at 0 to 12 months lags in time.

Table 3. Monthly distribution of birth and conception in the study troops*

\begin{tabular}{|c|c|c|c|c|c|c|c|c|c|c|c|c|c|}
\hline Year & Jan. & Feb. & Mar. & Apr. & May & June & July & Aug. & Sept. & Oct. & Nov. & Dec. & No. of births \\
\hline 1985 & & $2^{2 a}$ & $1^{\mathrm{a}}$ & & & & & & & & & & 3 \\
\hline 1986 & & & & $1^{\mathrm{b}}$ & & $3^{2 b, c}$ & & & & & & & 4 \\
\hline 1987 & & & & $3^{b, 2 d}$ & $1^{b}$ & $2^{a, b}$ & & & & & & & 6 \\
\hline 1988 & & & & & $2^{a, b}$ & & & & & & & & 2 \\
\hline 1989 & & & $3^{3 a}$ & $2^{a, b}$ & $2^{b, c}$ & & & & & & & & 7 \\
\hline 1990 & & & & $1^{b}$ & $4^{4 b}$ & & & $1^{c}$ & & & & & 6 \\
\hline Total & & 2 & 4 & 7 & 9 & 5 & 0 & 1 & & & & & 28 \\
\hline$(\%)$ & 0 & 7.1 & 14.3 & 25 & 32.1 & 17.9 & 0 & 3.6 & 0 & 0 & 0 & 0 & 100 \\
\hline
\end{tabular}

Monthly distribution of conception over the 6 years

$\begin{array}{lllllllllllllll}\text { (\%) } & 8.9 & 1.8 & 1.8 & 0 & 0 & 0 & 0 & 3.6 & 3.6 & 17.9 & 26.8 & 35.7 & 100\end{array}$

*Conception time is estimated to be 5.5 months before birth, when it falls between two successive months, each receives a score of 0.5 in frequency count. Superscript denotes the number of (a) nonlactating or (b) lactating multiparous females, or (c) 4-year- or (d) 5-year-old primiparous females that gave birth in each month.

Table 4. Annual birth rates of the study troops**

\begin{tabular}{llllllll}
\hline Troop & 1985 & 1986 & 1987 & 1988 & 1989 & 1990 & Average \\
\hline S & $1.00(3)$ & $1.00(4)$ & $0.86(7)$ & & & & 0.95 \\
S1 & & & & $0.67(3)$ & $1.00(4)$ & $1.00(5)$ & 0.89 \\
S2 & & & & $0.00(3)$ & $1.00(3)$ & $0.33(3)$ & 0.44 \\
\hline
\end{tabular}

*Number in parentheses indicates number of adult females in each troop in each year.

the distribution of births and monthly rainfall at different time lags $(0-12$ months $)$ were calculated to investigate the relation between rainfall and reproduction (Fig. 4). The maximum correlation coefficients occurred at eight to ten months before birth. This indicated that births occurred eight to ten months, or conceptions took place two to four months, after peak rainfall. It also implied that conception began in late rainy season or in the first two months of dry season, and birth occurred in early rainy season.

Reproductive history of individual females may affect the timing of birth. Nonlactating 
Table 5. Interbirth intervals for adult females.

\begin{tabular}{llll}
\hline Female & Sex of infants & Birth interval (months) & Average (months) \\
\hline$R$ & $\mathrm{M} / \mathrm{M} / \mathrm{F}$ & $13.5 / 13.5$ & 13.5 \\
$H$ & $\mathrm{~F} / \mathrm{F} / \mathrm{M} / \mathrm{F} / \mathrm{F} / \mathrm{F}$ & $16.0 / 10.5 / 13.0 / 11.0 / 12.0$ & $12.5(11.6)^{*}$ \\
$H 1$ & $\mathrm{~F} / \mathrm{F}$ & $12.0^{\dagger}$ & 12.0 \\
$X$ & $\mathrm{M} / \mathrm{F} / \mathrm{M} / \mathrm{M}$ & $23.0^{\dagger} / 12.5 / 12.0$ & 15.8 \\
$F$ & $\mathrm{~F} / \mathrm{M} / ?$ & $23.0^{\dagger} / 13.5$ & 18.3 \\
$E$ & $\mathrm{M} / \mathrm{F} / \mathrm{F} / \mathrm{M}$ & $14.5 / 12.0 / 21.5$ & 16.0 \\
$N$ & $\mathrm{M} / \mathrm{F} / ?$ & $24.0^{\dagger} / 13.5$ & 18.6 \\
$U$ & $\mathrm{~F} / \mathrm{M}$ & 21.0 & 21.0 \\
Average for all the intervales & & 15.4 \\
\hline
\end{tabular}

*The average excludes the first interval; finterval after first birth.

parous females gave birth significantly earlier than those who were nursing infants born in the preceding year (Kolmogorov-Smirnov two-sample test, one-tailed: $D=0.656, p<$ 0.01). Over the six birth seasons, nonlactating parous females gave birth in the months between February and June (mode $=$ March). Lactating females, however, gave birth between April and June (mode=May). This temporal pattern of breeding order by parous females is most obvious within the birth seasons of 1988 and 1989 when both kinds of parous females gave birth. In these two seasons, nonlactating females gave birth 0.5 to two months earlier than lactating females (Table 3). Although nonlactating female $U$ gave birth in June in 1987, it was considered an exception because it was released to the study area and had conceived and given birth before joining S2 troop. The five primiparous monkeys underwent first parturition between April and August (Table 3). The timing was probably related to their ages: 4-year-old females gave birth in the last month of each birth season, and the two 5-year-old females gave birth in the first month of the birth season in 1987.

\section{INTERBIRTH INTERVALS}

Intervals between successive births for all the parous females ranged from 10.5 to 24.0 months with an average of 15.4 months (Table 5). Because monkeys exhibited discret breeding seasons, females that failed to reproduce in one year had to wait for the next year. Therefore, interbirth intervals could readily be divided into two classes: one-year interval and two-year interval. The average length of time for the former was 12.8 months $(N=14)$, and 22.5 months for the latter $(N=5)$. Three of the four primiparous females gave birth at two-year interval, while 13 out of the 15 multiparous females gave birth at one-year interval.

Among all the females, $H$ is the most successful breeder, having six offspring in the six birth seasons. The average length of the intervals between successive births by $H(12.5$ months) is slightly shorter than that of all the one-year intervals (12.8 months). If we excluded the birth interval between 1985 and 1986 (16.0 months) which may have been extended because $H$ had an early birth in 1985, the average birth interval (11.6 months) became 1.2 months shorter than the averaged 12.8 months.

\section{SuRvival Rate}

Hunting is the major cause for disappearance of monkeys in the study area. Seven animals (five juveniles and two adult females) were considered to be dead during the study. Hunting was directly or indirectly responsible for the disappearance in five cases. Two 
females were hunted by local people: one female $(R)$ was captured in 1987 together with its 6-month-old offspring $(R 3)$, the other $(F)$ was shot in 1990 while the infant of less than 1 month old $(F 3)$ was captured by the hunter. Female $F$ was said to have escaped from the incidence with serious wound but never appeared again, and its 1-year-old offspring $(F 2)$ also disappeared after the event. Both were presumed dead. Two other juveniles $(F 1 \& R 2)$ disappeared at the age of 8 and 9 months. Although occurring in different years, both cases were in the winter time and were probably caused by some natural mortality factor. The survival rate for juveniles before 1.5 years of age was 0.8 . All the resident juveniles above 1.5 years old survived till the end of the study.

\section{DISPERSAL}

Four adult males ( $\sigma^{\circ} O, \sigma^{\prime} 1, \sigma^{\prime} 2, \& \sigma^{\prime} Y$ ) and one adult female $(U)$ who were not members of $\mathrm{S}$ troop joined the two daughter troops during the study. $U$ and ${ }^{\prime} O$ were released by people to nearby area in 1986, and the others might have dispersed from neighboring troops. All the four males had been troop-males for some periods of time and copulated with females. $U$ joined $\$ 2$ troop after the fission and gave birth twice during the study.

Four males were thought to have emigrated from the study troops (Table 2). Two of them $\left(O^{\circ} O \& \bigcirc^{\prime}\right.$ ) were once immigrants and left the troops after they have stayed for 15 and 19 months, respectively. They were sometimes seen wondering around and following the troops after they had left the troops. The original troop-male of $\mathrm{S}$ troop $\left(O^{\circ} M\right)$ joined $\mathrm{S} 1$ troop after the fission. $O M$ left $\mathrm{S} 1$ troop between November and December 1987, stayed with S2 troop for two to three months, and disappeared in February 1988. One juvenile male $(R I)$ in S1 troop, who was born into S troop in 1985 and whose mother was captured by local people in 1987 , left $\mathrm{S} 1$ troop six months after the disappearance of its mother. Prior to the disperal, $R l$ often rested and groomed with of $I$ ( $O^{\prime} l$ was a nontroop male then and it frequently approached S1 troop). After leaving S1 troop, $R I$ approached and moved around S2 troop for three months and disappeared at the age of 3.5 years.

\section{DISCUSSION}

Macaques generally live in multi-male social troops with troop sizes ranging from about 10 to more than 100 (CALDECOTT, 1986; MaKwaNA, 1978; MARUhashi, 1982; TAKASAKI, 1981; TAKASAKI \& MASUI, 1984). However, troop sizes of the Formosan macaques we studied were small, ranging from 10 to 20 over the study period. Recent surveys on this species in areas of different elevations, vegetations and human disturbance revealed that although medium-sized troops of 20-50 individuals were still common, small-sized troops of less than 20 animals were reported more often (KAWAMURA et al., 1988; LEE \& LIN, 1991; LIN \& LU, 1989, 1990; Lu et al., 1991; MASUI et al., 1986). Hunting pressure was thought to be the cause for small troop size and low population density of Formosan macaques (KawAmura et al., 1988; KAZAMA \& NorikOSHI, 1991; MASUI et al., 1986), and was also the reason for the small size of $S$ troop when we began our study. In the five years after hunting was banned, total number of monkeys in the study area increased from 10 to nearly 30 . However, instead of becoming one larger troop, $S$ troop split into two troops when it grew in size. Hence, the troop size never exceeded 20.

According to the result of other surveys (Kawamura et al., 1988; LiN \& LU, 1989, 1990; LU et al., 1991; MASUI et al., 1986), medium-sized troops might have two or more troop- 
males, while small-sized troops tended to have only one adult male. Small-sized one-male troops have also been found in an introduced population of Formosan macaques in Izu Ohshima Island, Japan (KAZAMA \& NoRIKOSHI, 1991). In our study, the monkey troops contained only one adult male most of the time. Some nontroop males were also found in the study area. They would sometimes approach the study troops and even copulate with females in the troops. It is interesting to know as the troops grow in size, whether they will become multimale troops that allow solitary males to join in or will split again into smaller troops led by former nontroop males.

Formosan macaques in Kenting are seasonal breeders, and the breeding seasonality is similar to what has been reported for wild-caught females (PENG et al., 1973) and zoo animals (CHENG, 1989). Breeding seasonality has been found in many macaque species (Estrada \& Estrada, 1976; Melnick \& Pearl, 1987) and may be regulated by internal physiological rhythms and external stimuli (LANCASTER \& LEE, 1965; ZhaO \& DenG, 1988). Since annual changes in temperature, rainfall, and daylength are highly correlated, it is difficult to determine the environmental cues for the observed pattern. However, in the present study, the onset of breeding was associated with decreasing daylength, falling temperature, and high level of rainfall, and this was similar to the association found in other species (LANCASTER \& LEE, 1965). LANCASTER and LEE (1965) also reported that the onset of conception for Japanese macaques was associated with the fall fruiting season. KOFORD (1965) thought that the onset of reproduction might depend upon food availability which was determined by the distribution of rainfall. In Kenting, fruiting activity peaks in the period from September to November (Ho, 1971) which coincides with the onset of mating season.

The ultimate explanation for breeding seasonality is that the timing of birth should be selected to insure the survival of offspring. One explanation is that births should occur in the period when food is abundant so as to meet the energetic demands of lactating females, and another saying is that births occur in the dry season in order to minimize the risk of postnatal death from exposure to the wet season (DunBAR, 1980; Horrocks, 1986). Most plant species in Kenting sprout in March and April, and the growth of new shoots and young leaves is accelerated in May and June by the presence of rain (Ho, 1971). Births in the study troops also occurred in this early rainy season when tender new growths are abundant and when the climatic condition is not too harsh for the neonates.

Although changes in environmental variables may determine the appropriate range of time for reproduction to occur, age, parity, and reproductive history of the females may also influence the timing of reproduction in more subtle ways (KUSTER \& PAUL, 1984; PAUL \& THOMMEN, 1984). In the present study, we found that parous females without infant from the preceding year gave birth earlier than lactating females whereas 4-year-old primiparous females gave birth later than other females in each birth season. The same observation was also reported in Barbary macaques and rhesus monkeys (DrICKAMER, 1974; Koford, 1965; Kuster \& PaUl, 1984; PAUl \& ThOMmen, 1984). Variation in the month of birth by primiparous females in Kenting was observed. This may be related to the actual age of the monkeys. For example, there is a three-month difference in the time of first birth by $\mathrm{Hl}$ and $H 2$, but the actual ages when they gave the first birth are about the same (51 months vs. 50.5 months). PENG et al. (1973) found that, although menarche occurred at ages $31.4-46.4$ months with a body weight range of $1.9-3.8 \mathrm{~kg}$, female Formosan macaques in captivity could not conceive unless they weighed more than $4 \mathrm{~kg}$. For the wild macaques in Kenting, females underwent first sign of changes in sexual skin at 2.5 years of age, and had conceived one or two years later. There may be a threshold of age or body weight, 
which in turn reflects the nutritional or developmental status of the animals, for females to start breeding.

Reproductive parameters of Formosan macaques are more similar to rhesus than to Japanese macaques. Total birth rate over the six birth seasons $(80 \%)$ is similar to that of many rhesus troops (70-91\%; DrICKAMER, 1974; KoFORD, 1965; MAKWANA, 1978; MALIK et al., 1984; SOUTHWICK \& SIDDIQI, 1977; WOLFE, 1986), but is higher than that of provisioned and wild troops of Japanese macaques (32-73\%; IKEDA, 1982; MARUHASHI, 1982; Mori, 1979; Sugiyama \& OHSAWA, 1982; TAKahata, 1980; Wolfe, 1986). Ages of first parturition for Formosan macaques (PENG et al., 1973; this study) and rhesus (DrICKAMER, 1974; WOLFE, 1986) are between 4 and 5 years of age which are 1 to 2 years earlier than the ages reported for Japanese macaques (Mori, 1979; SugrYama \& OHSAWA, 1982; TAKAHATA, 1980; WOLFE, 1986). The average interbirth interval of Formosan macaques (15.4 months) is one month longer than that of a rhesus troop (14.3 months), but three months shorter than that of a troop of Japanese macaques (18.0 months) (WOLFE, 1986). In our study troops, one nonreproductive year after the first birth was observed in all but one primiparous females. In Takagoyama-I troop of Japanese macaques, young females 5 to 9 years old never gave birth in successive years (HIRAIwA, 1981). In one Barbary macaque troop, interbirth interval after the first birth was longer than that after subsequent births, and the percentage of two-year intervals was higher in primiparous females than in multiparous mothers (PAUL \& THOMMEN, 1984).

Annual birth rates of S and S1 troops were higher than that of the S2 troop. The lower birth rate in S2 troop might be related to its social organization and physical condition of the females. After the fission in 1987, or $O$ joined S2 troop but its relationship with the females of the troop was unstable, especially during the mating season of 1987 when it was sometimes seen to have left S2 troop and approached and copulated with females of S1 troop. The unstable relationship between ${ }^{\circ} O$ and the females of $\mathrm{S} 2$ troop might well have made the females unable to conceive in late 1987.

Among the three adult females in S2 troop, two of them $(E \& U)$ have bred only once in the three birth seasons. $E$ looked older than all the other females in both troops. Whereas $U$, being a handicap with only one palm and released into the study area by local people, was unable to form intimate relationship with troop-mates and sometimes moved away from S2 troop. The physical condition and social status of these two females may have affected their breeding success.

A female's dominant rank within a social troop may affect its fecundity and the number of surviving offspring. Shorter birth interval, higher birth rate, higher offspring survival, and growth rates of high-ranking females have been reported in other macaque species (e.g. Drickamer, 1974; Mori, 1979; Silk et al., 1981; SugiYama \& OhSAWA, 1982; Takahata, 1980 ). But in some studies there was no positive correlation between female dominance rank and reproductive success (Gouzoules et al., 1982; CHENEY et al., 1988). Although we did not assess the dominant relationship among the animals, it is obvious from our observations that $\boldsymbol{H}$ is the most dominant female in $\mathrm{S}$ and $\mathrm{S} 1$ troops. During the study period, $H$ gave birth in all the six birth seasons and all its six offspring survived till the end of the study. The intervals between successive births for $H$ were shorter than the average.

Two daughters of $H(H I \& H 2)$ probably inherited $H$ 's dominance rank and obtained the advantages from being dominant within the troop. Both conceived in their first fertile season at 3.5 years old, which was 1 year earlier than the ages of first conception for females $F$ and $N$. Moreover, the eldest daughter of $H$ was the only young female that gave its first two births in two successive years. DRICKAMER (1974) and ALTMANN et al. (1988) 
reported that in rhesus monkeys and yellow baboons, daughters of high ranking females matured and bred earlier than did the daughters of low ranking females. There were also some studies where no difference in the age of first parturition among high- and low-ranking females was observed (SILK et al., 1981; CHENEY et al., 1988). The higher reproductive success of the females in the matriline of $H$ may be a special case, more data are needed to determine the relationship between dominant rank and reproductive success within social troops of Formosan macaques.

Another interesting finding was that $H$, being the most dominant female in the troop, has more daughters than sons $\left(5 \%\right.$ vs. $\left.10^{\circ}\right)$. Argues exist on whether dominant females would have more daughters or sons (Altmann et al., 1988; PaUl \& THOMMEN, 1984; MEIKLE et al., 1984). Although what we have observed might be a biased result, the outcome of this biased offspring sex ratio is that at least ten of the 16 members of S1 troop are descendants from a single matriarch $(H)$. This result, together with the fact that the fission of S troop occurred along matrilines (WU et al., 1991), implies that the interindividual relatedness within S1 troop may be high. When monkey population is recovered from such small troops, genetic differentiation between troops may be high.

Similar to other macaque species, dispersal of the Formosan macaque is male-biased. The age for young males to disperse from their natal troops could not be determined in the present study. Adult males frequently changed troops (twice in three years for S1 troop), thus probably reducing the potential of inbreeding between males and their daughters (PUSEY \& PACKER, 1987) and the level of genetic differentiation between troops (MELNICK \& PEARL, 1987).

Acknowledgements. The authors wish to thank the Hengchun Branch of Taiwan Forestry Research Institute for granting permission to carry out the study in the preserve. We are also grateful to Dr. Syunzo Kawamura for many useful advice over the years. We thank Dr. Koshi Norikoshi for his helpful discussions and reviewing the draft of this paper. H.Y.W. is greatly indebted to Dr. LING-LiNG LEE for constructive advice; Mr. S. G. WU and his family for their hospitality over the years. This research was financially supported by the Council of Agriculture, Republic of China.

\section{REFERENCES}

Altmann, J., G. Hausfater, \& S. A. Altmann, 1988. Determinants of reproductive success in savannah baboons, Papio cynocephalus. In: Reproductive Success, T. H. ClutTon-Brock (ed.), Univ. of Chicago Press, Chicago, pp. 403-418.

Caldecott, J. D., 1986. Mating patterns, societies and the ecogeography of macaques. Anim. Behav., 34: 208-220.

Cheney, D. L., R. M. Seyfarth, S. J. Andelman, \& P. C. Lee, 1988. Reproductive success in vervet monkeys. In: Reproductive Success, T. H. CuUtTon-Brock (ed.), Univ. of Chicago Press, Chicago, pp. $384-402$.

Cheng, J. N., 1989. Sexual behaviour and parental care of Formosan macaque (Macaca cyclopis) in Taipei City Zoo. Master thesis, National Taiwan Univ. (in Chinese)

DrickAMER, L. C., 1974. A ten-year summary of reproductive data for free-ranging Macaca mulatta. Folia Primatol., 21: $61-80$.

Dunbar, R. I. M., 1980. Demographic and life history variables of a population of gelada baboons (Theropithecus gelada). J. Anim. Ecol., 49: 485-506.

EstradA, A. \& R. ESTRADA, 1976. Birth and breeding cyclicity in an outdoor living stumptail macaque (Macaca arctoides) group. Primates, 17: 225-231. 
Gouzoules, H., S. Gouzoules, \& L. Fedigan, 1982. Behavioural dominance and reproductive success in female Japanese monkeys (M. fuscata). Anim. Behav., 30: 1138-1151.

Hiraiwa, M., 1981. Maternal and alloparental care in a troop of free-ranging Japanese monkeys. Primates, 22: 309 - 329.

Ho, F. C., 1971. Investigation on flowering period, fruiting period, flower color and fruit color of plants of Heng-chun Tropical Botanic Garden in Taiwan (cont.). Ann. Taiwan Museum, 14: 47-60. (in Chinese)

Horrocks, J. A., 1986. Life history characteristics of a wild population of vervets (Cercopithecus aethiops sabaeus) in Barbadors, West Indies. Int. J. Primatol, 7:31-47.

IKEDA, H., 1982. Population changes and ranging behaviour of wild Japanese monkeys at Mt. Kawaradake in Kyushu, Japan. Primates, 23: 338-347.

Kawamura, S., N. Azuma, \& K. Norikoshi, 1988. Socio-ecological study of free-living Formosan monkeys (Macaca cyclopis) in Taipingshan Natural Park. Phys. Anthrop. Sect., Life Sci. Inst., Sophia Univ, Tokyo.

Kazama, K. \& K. Norikoshi, 1991. Formosan monkeys in Ohshima Island, Japan. Genetics, 45: $51-55$. (in Japanese)

Koford, C. B., 1965. Population dynamics of rhesus monkeys on Cayo Santiago. In: Primate Behavior, I. DeVore (ed.), Holt, Rinehart, \& Winston, New York, pp. 160-174.

Kuster, J. \& A. PAul, 1984. Female reproductive characteristics in semifree-ranging barbary macaques (Macaca sylvanus L. 1758). Folia Primatol., 43: 69-83.

LANCASter, J. B. \& R. B. LEE, 1965. The annual reproductive cycle in monkeys and apes. In: Primate Behavior, I. DeVore (ed.), Holt, Rinehart, \& Winston, New York, pp. 486-513.

LeE, L. L. \& Y. S. LiN, 1991. Status of Formosan macaques in Taiwan. In: Primatology Today, Proceedings of the XIIIth Congress of the International Primatological Society, A. EHARA, T. Kimura, O. Takenaka, \& M. Iwamoto (eds.), Elsevier Sci. Publ. B. V., Amsterdam, pp. 33- 36.

LIN, Y. S. \& J. F. LU, 1989. The ecological study of Formosan macaques (Macaca cyclopis) in the East-West Cross-island Highway between Taroko and Wenshan. Taroko National Park. (in Chinese)

- \& $\longrightarrow$ 1990. The ecological study of Formosan macaques (Macaca cyclopis) in the East-West Cross-island Highway between Wenshan and Dayulin. Taroko National Park. (in Chinese)

LU, J. F., Y. S. LIN, \& L. L. LEe, 1991. Troop composition, activity pattern and habitat utilization of Formosan macaque (Macaca cyclopis) at Nanshi logging road in Yushan National Park. In: Primatology Today, Proceedings of the XIIIth Congress of the International Primatological Society, A. Ehara, T. Kimura, O. Takenaka, \& M. Imamoto (eds.), Elsevier Sci. Publ. B. V., Amsterdam, pp. $93-96$.

MaKwana, S. C., 1978. Field ecology and behaviour of the rhesus macaque (Macaca mulatta). I. Group composition, home range, roosting sites, and foraging routes in the Asarori forest. Primates, 19: $483-492$.

Malik, I., P. K. SETH, \& C. H. Southwick, 1984. Population growth of free-ranging rhesus monkeys at Tughlaqabad. Amer. J. Primatol., 7: $311-321$.

Maruhashi, T., 1982. An ecological study of troop fissions of Japanese monkey (Macaca fuscata yakui) on Yakushima Island, Japan. Primates, 23: 317-337.

MASUI, K., Y. NARFTA, \& S. TANAKA, 1986. Information on the distribution of Formosan monkeys (Macaca cyclopis). Primates, 27: 383- 392.

Meikle, D. B., B. L. Tilford, \& S. H. Vessey, 1984. Dominance rank, secondary sex ratios, and reproduction of offspring in polygynous primates. Amer. Naturalist, 124: 173-188.

Melnick, D. J. \& M. C. PEARL, 1987. Cercopithecines in multimale groups: genetic diversity and population structure. In: Primate Societies, B. B. Smuts, D. L. Cheney, R. M. Seyfarth, R. W. Wrangham, \& T. T. Struhsaker (eds.), The Univ. of Chicago Press, Chicago, pp. $121-134$.

Mori, A., 1979. Analysis of population changes by measurement of body weight in the Koshima troop of Japanese monkeys. Primates, 20: 371-397.

Paul, A. \& D. Thommen, 1984. Timing of birth, female reproductive success and infant sex ratio in semifree-ranging Barbary macaques (Macaca sylvanus). Folia Primatol., 42: 2-16.

Peng, M.-T., Y.-L. Lal, C.-S. YAng, H.-S. ChianG, A. E. New, \& C.-P. Chang, 1973. Reproductive parameters of the Taiwan monkey (Macaca cyclopis). Primates, 14: $201-213$. 
Poirier, F. E. \& D. M. Davidson, 1979. A preliminary study of the Taiwan macaque. Quart. J. Taiwan Museum, 32: $123-191$.

Pusey, A. E. \& C. PACKer, 1987. Dispersal and philopatry. In: Primate Societies, B. B. Smuts, D. L. Cheney, R. M. Seyfarth, R. W. Wrangham, \& T. T. Struhsaker (eds.), The Univ. of Chicago Press, Chicago, pp. 250-266.

Silk, J. B., C. B. Clark-Wheatley, P. S. Rodman, \& A. Samuels, 1981. Differential reproductive success and facultative adjustment of sex ratios among captive female bonnet macaques (Macaca radiata). Anim. Behav., 29: 1106-1120.

Southwick, C. H. \& M. F. SidDiQI, 1977. Population dynamics of rhesus monkeys in northern India. In: Primate Conservation, Prince Rainier III \& G. H. Bourne (eds.), Academic Press, New York, pp. $339-362$.

Sugiyama, Y. \& H. OhsaWA, 1982. Population dynamics of Japanese monkeys with special reference to the effect of artificial feeding. Folia Primatol., 39: 238-263.

TAKAHATA, Y., 1980. The reproductive biology of a free-ranging troop of Japanese monkeys. Primates, 21: 303-329.

TAKASAKI, H., 1981. Troop size, habitat quality, and home range area in Japanese macaques. Behav. Ecol. Sociobiol., 9: 277-281.

- \& K. MASUI, 1984. Troop composition data of wild Japanese macaques reviewed by multivariate methods. Primates, 25: $308-318$.

TANAKA, S., 1986. Further note on the distribution problems of the Formosan monkey (Macaca cyclopis). Kyoto Univ. Overseas Res. Report of Studies on Nonhuman Primates, 5: 95-104.

WolfE, L. D., 1986. Reproductive biology of rhesus and Japanese macaques. Primates, 27: 95-102.

Wu, H. Y., 1986. The behavioral and ecological study of the Taiwan macaque (Macaca cyclopis) in Kenting area. Master thesis, National Taiwan Univ. (in Chinese)

Y. S. LiN, \& L. L. LeE, 1991. Demography of a wild troop of Formosan macaque in Kenting, southern Taiwan. In: Primatology Today, Proceedings of the XIIth Congress of the International Primatological Society, A. Ehara, T. Kimura, O. TAKenaka, \& M. Inamoto (eds.), Elsevier Sci. Publ. B. V., Amsterdam, pp. 29-32.

Zhao, Q. \& Z. Deng, 1988. Macaca thibetana at Mt. Emei, China: II. Birth seasonality. Amer. J. Primatol., 16: $261-268$. 